\title{
Multiscale analysis of the thermal degradation of polyamide 6,6: Correlating chemical structure to mechanical properties
}

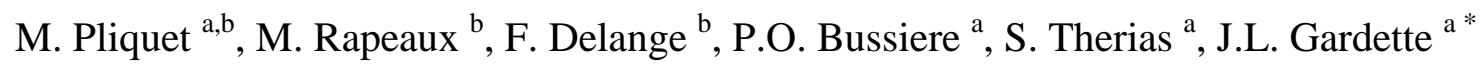 \\ ${ }^{a}$ Université Clermont-Auvergne-CNRS-SIGMA, Institut de Chimie de Clermont-Ferrand, Campus \\ des Cézeaux, 24 Avenue Blaise Pascal, TSA 60026, CS 60026, 63178 Aubière Cedex, France
}

${ }^{\mathrm{b}}$ Schneider Electric, Site Electropôle, 31 rue Pierre Mendès France, F-38320 Eybens, France.

*Corresponding author:

I.C.C.F, UMR 6296 - Institut de Chimie de Clermont-Ferrand, Université Clermont Auvergne - CNRS - SIGMA Clermont Campus des Cézeaux - 24, avenue Blaise Pascal - TSA 60026 CS 6002663178 Aubière Cedex, France. E-mail address: luc.gardette@uca.fr (J.L. Gardette).

\begin{abstract}
In this paper, the thermal oxidation of polyamide 6,6 between $140{ }^{\circ} \mathrm{C}$ and $200{ }^{\circ} \mathrm{C}$ is evaluated. The aim of this study is to correlate the modifications of the polymer properties on scales ranging from molecular to macroscopic. Chemical structure changes are monitored by infrared and UV-visible spectroscopies. The modifications of the microstructure are evaluated using DSC while molar mass evolution is determined by SEC measurements. Vickers $\mu$ hardness is used to assess the mechanical properties. Although the carbonyl index is frequently used to measure the extent of oxidation, this article employs the overtone of the amide II band $\left(3080 \mathrm{~cm}^{-1}\right)$ as a more relevant criterion to quantify the oxidation of polyamide. This criterion allows for an earlier detection of the thermo-oxidation of polyamides and is well-correlated with modifications of the polymer properties. Direct correlations are observed between changes in the chemical structure, modification of the microstructure and the thermal/mechanical properties, regardless of the measurement scale. It is shown that the variations in the intensity of this band fit well with the changes in the crystallinity, molar
\end{abstract}


mass, molecular mobility and micro hardness, validating the multiscale characterization model.

Keywords: Polyamide 6,6, thermo-oxidative degradation, multi-scales, crystallinity

\section{1) Introduction}

Polyamides are one of the first and most important families of engineering plastics because of their excellent properties, such as high resistance to mechanical stresses (tensile strength, fatigue behaviour, stiffness) and chemical substances (e.g., oils, greases, solvents), and good dielectric properties. These remarkable properties have led to the wide use of polyamides in various industrial fields, such as automotive, textile, electrical distribution and offshore fields. [1] Concerning the long-term applications of polyamides, their performance in ambient atmosphere is a critical factor. It is therefore of technical and commercial importance to predict the effective lifetime of the material for its applications. In circuit breakers, where polyamide 6,6 is used as an electric insulation component, the service temperature is typically within the range of $60{ }^{\circ} \mathrm{C}$ to $80{ }^{\circ} \mathrm{C}$ and may reach $110{ }^{\circ} \mathrm{C}$ in some harsh conditions. These elevated temperatures combined with the presence of oxygen can cause a thermo-oxidative ageing of the material which leads to the deterioration of its properties. Insulating materials should maintain their properties over a long period of time during service life. Rapid and easy test methods allowing for an early detection of material degradation are required to predict their lifetime.

The thermo-oxidative ageing of polyamides involves several chemical and physical processes followed by structural changes leading to a deterioration of the functional properties of the material. There are several functional properties that can be impacted: electrical [2-4], mechanical [5], optical, aesthetic etc. Because there is not a single origin for the deterioration of the properties, clarifying the mechanism is of great significance both in theory and in practice. It is then important to characterize the degradation of the material entirely, from the molecular to the macroscopic scale. Many studies have been carried out focusing on characterization of the thermal oxidation of polyamides. Several analytical techniques were used, which have the capability to characterize the modifications of the material during the successive stages of degradation. Chemical changes in the polyamide matrix have been measured by infrared and UV/Vis spectroscopies [6,7], photoacoustic [8], luminescence [9- 
12] and gas chromatography [13]. The consequences of the chemical changes have been investigated by tensile tests, rheology in the melting state, differential scanning calorimetry, $\mathrm{X}$-ray diffraction etc. However, there is still a lack of knowledge on the cross-correlations between the various properties affected by thermo-oxidative ageing. The present article pays particular attention to correlations between the chemical changes in the PA matrix and the deterioration of its functional properties using relevant degradation indicators.

The present study has two main objectives: (1) to evaluate the impact of thermo-oxidation of PA 6,6 on the modifications at the molecular level, the changes in the microstructure and macromolecular architecture as well as the loss in functional properties. (2) to correlate relevant chemical probes for measuring oxidation to the modification of the different properties from the molecular to the macroscopic scale.

\section{2) Experimental}

\section{1) Materials}

The experimental raw material is commercial grade polyamide 6,6 supplied by Dupont ${ }^{\mathrm{TM}}$ $\left(Z_{\text {Ztel }}{ }^{\circledR} 101 \mathrm{~L}\right)$. The samples were injection-moulded directly onto plates $(80 \times 80 \mathrm{~mm})$ with a thickness of $1.5 \mathrm{~mm}$ and films with thicknesses ranging from 200 to $400 \mu \mathrm{m}$ were obtained. After moulding, materials were kept in special containers in order to prevent any moisture uptake before thermal ageing.

\section{2) Oven ageing}

Thermo-oxidative ageing was carried out in a forced air venting oven (Memmert UF30) at temperatures between $140{ }^{\circ} \mathrm{C}$ and $200{ }^{\circ} \mathrm{C}$. The samples were collected after different time intervals up to $3000 \mathrm{~h}$. A minimum of three samples were prepared and characterised per ageing time to ensure reproducibility of the measurements.

Ageing was also performed in the absence of oxygen in a vacuum chamber. The oven was coupled with a vacuum pump and a pressure of $10^{-31}$ mbar was applied. The experiments were carried out in the same temperature range and time intervals as thermo-oxidative ageing. 


\section{3) Characterization techniques}

\section{3.a) FTIR spectroscopy}

After thermal ageing, the samples were analysed by infrared spectroscopy in transmission mode using a Nicolet 6700 spectrophotometer and in attenuated total reflection mode (ATR) using a Nicolet 380 spectrophotometer equipped with a diamond crystal (refractive index = 2.5). Spectra were recorded with 64 scans at a resolution of $4 \mathrm{~cm}^{-1}$. In the spectra obtained with the ATR mode, the angle of incidence is specified at $45^{\circ}$ and the refractive index of the material is set at 1.5. In order to correct the wavelength-dependent penetration depth, we used the Omnic software produced by ThermoScientific. Moreover, the $\mathrm{CH}_{2}$ scissor band at 1463 $\mathrm{cm}^{-1}$ was chosen as a reference band because of its insensitivity to the oxidation process. The absorbances at the various maxima considered were corrected using the absorbance of the reference band.

\section{3.b) Differential scanning calorimetry}

Differential scanning calorimetry was performed with a Mettler Toledo DSC 3+ device. The samples were cut on plates and heated from $25{ }^{\circ} \mathrm{C}$ to $300{ }^{\circ} \mathrm{C}$ at a heating rate of $10{ }^{\circ} \mathrm{C} / \mathrm{min}$ under air flow. This analysis was carried out to determine changes in the semi-crystalline morphology of PA 6,6. A standard heat of melting $\left(\Delta \mathrm{H}_{\mathrm{f}}\right)$ of $196 \mathrm{~J}^{-\mathrm{g}^{-1}}$ for $100 \%$ crystalline PA 6,6 was used to calculate the crystallinity, as defined by equation (1):

$$
\mathrm{X}_{\mathrm{c}}=\frac{\Delta \mathrm{H}_{\mathrm{f}}}{\Delta \mathrm{H}_{\mathrm{f}}{ }^{0}}
$$

\section{3.c) Size exclusion chromatography}

Size exclusion chromatography measurements were performed to follow the changes in average molar mass $M_{n}$ and $M_{w}$ during oxidative ageing. First, the samples were dissolved in 
1,1,1,3,3,3-hexafluoroisopropanol (HFIP) at a concentration of approximately 2 g.L ${ }^{-1}$. The dissolution was carried out at room temperature for $24 \mathrm{~h}$. Then, the samples were filtered through a PTFE $0.2 \mathrm{~mm}$ membrane, and $50 \mu \mathrm{L}$ was injected into the chromatograph equipped with two columns of the same dimension $8 \mathrm{~mm}$ x $300 \mathrm{~mm}$. The columns were packed with 10 $\mu \mathrm{m}$ particles with $1000 \AA$ and $100 \AA$ pore sizes. Analyses were performed at $40{ }^{\circ} \mathrm{C}$ at a flow rate of $1 \mathrm{ml} / \mathrm{min}$ with a mixture of HFIP/0.1 mol. $\mathrm{L}^{-1}$ potassium trifluoroacetate the eluant. The calibration was performed using poly(methylmethacrylate) standards.

\section{3.d) DMTA}

A TA Instruments Q800 dynamic mechanical analyzer was used to determine the dynamic mechanical properties of unaged and aged PA 6,6. Rectangular samples of 40 x $10 \times 1,5 \mathrm{~mm}$ were tested in single cantilever mode in a temperature range from $25^{\circ} \mathrm{C}$ to $200{ }^{\circ} \mathrm{C}$ at a heating rate of $3{ }^{\circ} \mathrm{C} / \mathrm{min}$. The frequency was fixed at $1 \mathrm{~Hz}$ with an applied strain of $0,05 \%$.

\section{3.e) UV/Vis spectroscopy}

The UV-Vis spectra of the polymer were recorded with a Shimadzu UV-2600 scanning spectrophotometer equipped with an integrating sphere, working with UVProbe software. Measurements were performed with polymer plates $(1500 \mu \mathrm{m})$. The spectra were recorded in transmission mode by analysis the $1.5 \mathrm{~mm}$ plates, which were transparent enough to obtain absorbances in a convenient range $(\mathrm{A}<3)$. The degree of yellowing is determined by plotting the absorbance at $450 \mathrm{~nm}$.

\section{3.f) Vickers micro-hardness}

The hardness of a sample was determined by applying a pyramidal tip under load on the surface of a PA 6,6 plate and measuring the penetration. The measurements were performed using a Shimadzu HMV hardness tester and indentations were created at a load of $2 \mathrm{~N}$ with a holding time of $10 \mathrm{~s}$. The Vickers microhardness values were calculated by equation (2):

$$
\mathrm{H}_{\vartheta}=\mathrm{k} \times 10^{6} \times \frac{\mathrm{P}}{\mathrm{d}^{2}}
$$


where $\mathrm{P}$ is the load applied $(\mathrm{N}), \mathrm{d}$ is the average diagonal of the Vickers indentation $(\mathrm{mm})$ and $\mathrm{k}$ is a geometrical factor equal to 1,854 . [14]

\section{3) Results and discussion}

3.1) Modification of the chemical structure

\section{1.a) FT-IR analysis}

Infrared spectroscopy is one of the most common ways to investigate oxidative ageing, notably the formation of carbonyl species. [15-17] IR spectroscopy was applied to identify the characteristic bonds present in the chemical configuration of polyamide 6,6 . The complete band assignment of PA 6,6 was studied by several authors [18-24]. The spectrum of the polymer before ageing and the frequencies of the bands with their proposed assignments are shown in Fig.1.

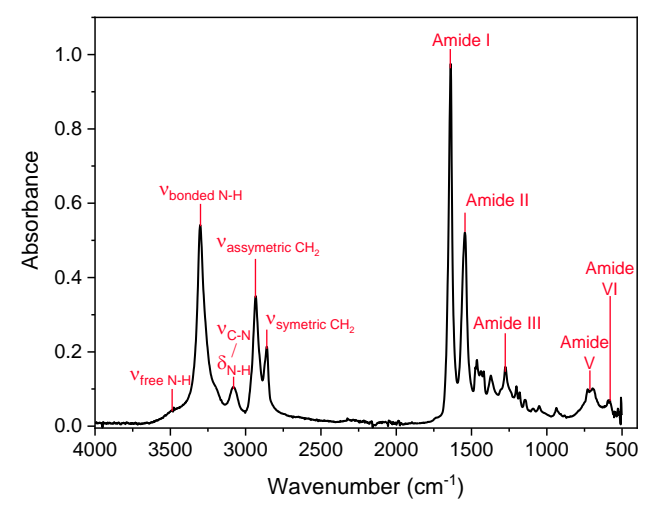

\begin{tabular}{|c|c|c|}
\hline $\begin{array}{c}\text { Wavenumber } \\
\left(\mathrm{cm}^{-1}\right)\end{array}$ & Assignment & Ref \\
\hline 3488 & "Free" N-H stretching & {$[18]$} \\
\hline 3300 & "Bonded" N-H stretching & {$[18]$} \\
\hline $3100-3070$ & Overtone of Amide II band & [19] \\
\hline 3080 & $\begin{array}{c}\text { Overtone of } \mathrm{N}-\mathrm{H} \\
\text { deformation }\end{array}$ & [24] \\
\hline 2930 & Asymmetric $\mathrm{CH}_{2}$ stretching & {$[20]$} \\
\hline 2850 & Symmetric $\mathrm{CH}_{2}$ stretching & {$[20]$} \\
\hline 1638 & Amide $\mathrm{I}(\mathrm{C}=\mathrm{O}$ stretching $)$ & {$[21]$} \\
\hline 1545 & $\begin{array}{c}\text { Amide II (N-H deformation } \\
\text { and C-N stretching) }\end{array}$ & [19] \\
\hline 1476 & $\mathrm{CH}_{2}$ deformation $(\alpha-\mathrm{N})$ & {$[18]$} \\
\hline 1466 & $\mathrm{CH}_{2}$ deformation & {$[18]$} \\
\hline 1440 & N-H deformation & {$[24]$} \\
\hline
\end{tabular}

Fig.1 FTIR spectrum of PA 6,6 before ageing with frequencies and proposed assignments of the characteristic bands

Exposing PA 6,6 to conditions causing its oxidative degradation led to a dramatic modification of the chemical structure of the material. The ATR-IR spectra showed a 
progressive increase in the absorbance between 1820 and $1680 \mathrm{~cm}^{-1}$, and a notable shoulder was formed with various absorption maxima. Fig.2a shows a magnified view of the carbonyl species region (1900-1500 $\mathrm{cm}^{-1}$ ) of the samples aged at $140{ }^{\circ} \mathrm{C}$ between 0 and $2000 \mathrm{~h}$, and Fig. $2 \mathrm{~b}$ shows the region at $3150-3000 \mathrm{~cm}^{-1}$.
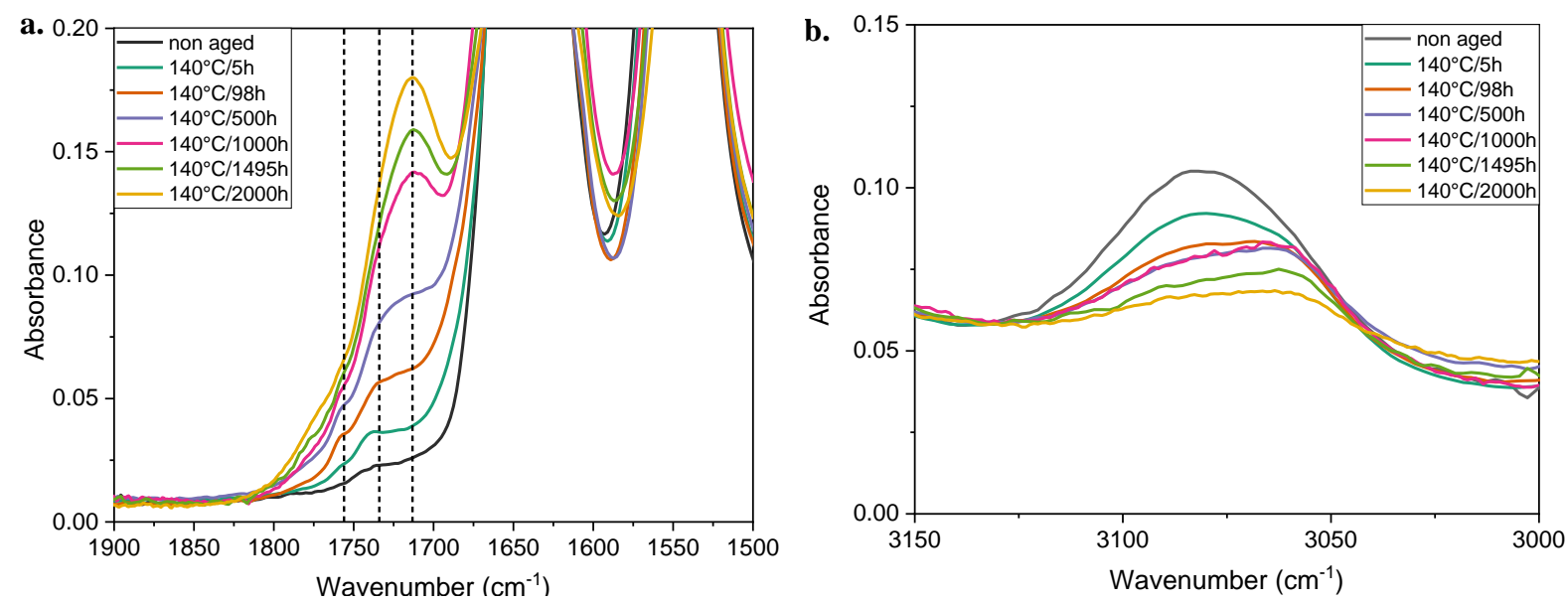

Fig.2 ATR-FTIR spectra of the carbonyl region (2a. left) and the 3150-3000 $\mathrm{cm}^{-1}$ region (2b. right) of PA 6,6 thermo-oxidized at $140{ }^{\circ} \mathrm{C}$

During the first period, the main observed band showed an absorption maximum at $1734 \mathrm{~cm}^{-1}$, and progressively the absorbance increased, and the maximum shifted to $1712 \mathrm{~cm}^{-1}$. In addition, the formation of a shoulder band at $1756 \mathrm{~cm}^{-1}$ was observed. It should be noted that these bands overlapped after long periods of time. It is worth mentioning that in many papers [22,23,25,26], the absorbance at $1734 \mathrm{~cm}^{-1}$ was chosen to quantify the extent of oxidation. The absorption maximum at $1712 \mathrm{~cm}^{-1}$ has not been often selected because the extent of oxidation reached is too low. In the domain $3150 \mathrm{~cm}^{-1}-3000 \mathrm{~cm}^{-1}$, the progressive disappearance of the band at $3080 \mathrm{~cm}^{-1}$ was observed, which was assigned to an overtone of the amide II band [18-20] resulting from the combination of $\mathrm{N}-\mathrm{H}$ bond deformation and C-N bond stretching of amide group.

The oxidation of polyamides provoked by exposure to UV-light or by increasing the temperature has been extensively studied in the past 50 years. The accepted mechanism is largely based on the pioneering work of Sagar [27], who focused on the thermal oxidation of $\mathrm{N}$-alkyl amides in the liquid phase. Since then, the photooxidation and thermo-oxidation of polyamides have received much attention in the literature, and mechanisms accounting for the modification of the chemical structure have been proposed. [22,23,25,26] In the case of thermo-oxidation, Okamba-Diogo et al. deconvoluted the broad carbonyl band and obtained 
three peaks at $1756 \mathrm{~cm}^{-1}, 1734 \mathrm{~cm}^{-1}$ and $1711 \mathrm{~cm}^{-1}$ attributed to isolated carboxylic acids, imides and carboxylic acids respectively. [28] Because of these studies, the absorption maxima observed in Fig. 2a can be assigned to different products. (Table.1.)

Table.1. Band assignments and corresponding wavenumbers of the oxidative species in polyamides

\begin{tabular}{|c|c|}
\hline Species & Wavenumber $\left(\mathrm{cm}^{-1}\right)$ \\
\hline "Free" carboxylic acids & 1756 \\
\hline Imides & 1734 \\
\hline "Bonded" carboxylic acids & 1712 \\
\hline
\end{tabular}

It is well-known that polyamide thermo-oxidation involves a radical chain mechanism with high selectivity. The initial stage of polymer oxidation is the thermal decomposition of hydroperoxide groups. [5] This decomposition can be unimolecular or bimolecular and leads to the formation of some very reactive species (hydroxyl and alkoxyl radicals). The oxidative attack is preferentially localized on the $\mathrm{C}-\mathrm{H}$ bonds in the $\alpha$ position of nitrogen atoms (see Fig.3). A radical is generated by removing the most labile hydrogen atom, which reacts and forms hydroperoxides. From the generation of these radicals, several reactions exist leading to the formation of oxidation products (the main routes of oxidation are illustrated by the mechanism shown in Fig. 3):

(a) The rearrangement of an alkoxy radical by $\beta$-scission causes the cleavage of C-N bonds. This $\beta$-scission results in the formation of primary amide and aldehyde. [29]

(b) The abstraction of hydrogen induces $\beta$-scission leading to the production of a macroradical and a formylamide.

(c) The formation of imides results from the disproportionation process of secondary alkyl radicals. [13,30]

(d) Hydrogen abstraction by macroalkoxy radicals leads to the production of unstable alcohols, which decompose into primary amides and aldehydes. Such aldehydes can rapidly be converted into carboxylic acids in the presence of oxygen as a result of prolonged ageing. [31] 


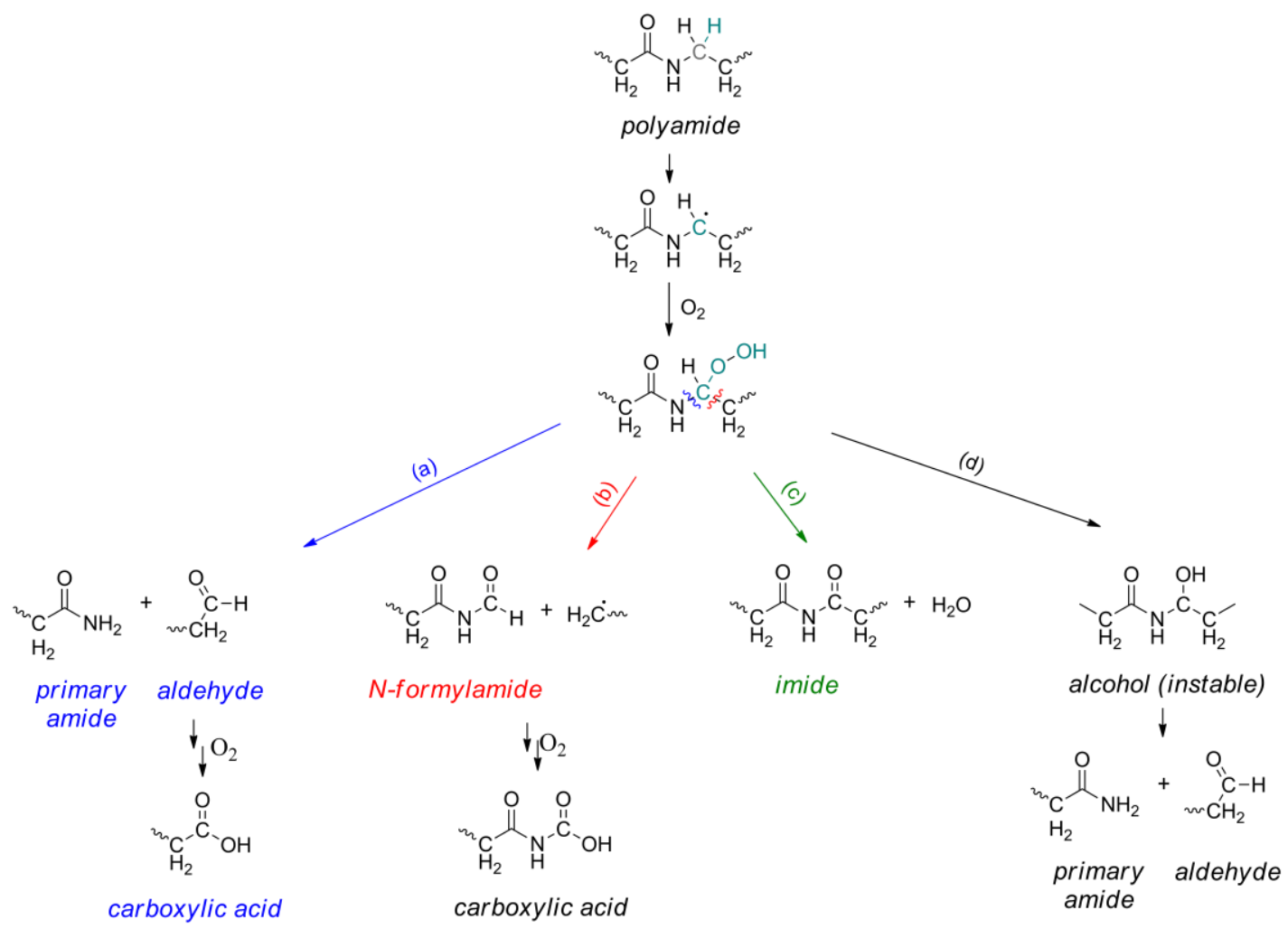

Fig.3 Mechanism of the thermo-oxidation of PA 6,6

Furthermore, the mechanism shown in Fig.3 indicates that hydroperoxides, identified as the primary oxidation products, involve abstraction of the most labile hydrogen in the $\alpha$ position of the $\mathrm{C}-\mathrm{N}$ bond. Regardless of the predominant degradation mechanism, the $\mathrm{C}-\mathrm{N}$ bond of the amide group is then affected, which explains the progressive disappearance of the band at $3080 \mathrm{~cm}^{-1}$.

The kinetic curves of oxidation can be plotted following the absorbance at $1734 \mathrm{~cm}^{-1}$, which reflects the formation of imides, mainly resulting from pathway (c) or $1712 \mathrm{~cm}^{-}$for the various temperatures of oxidation (Fig.4.a and b). One can also follow the variations in the absorbance at $3080 \mathrm{~cm}^{-1}$ (Fig. 4c). 

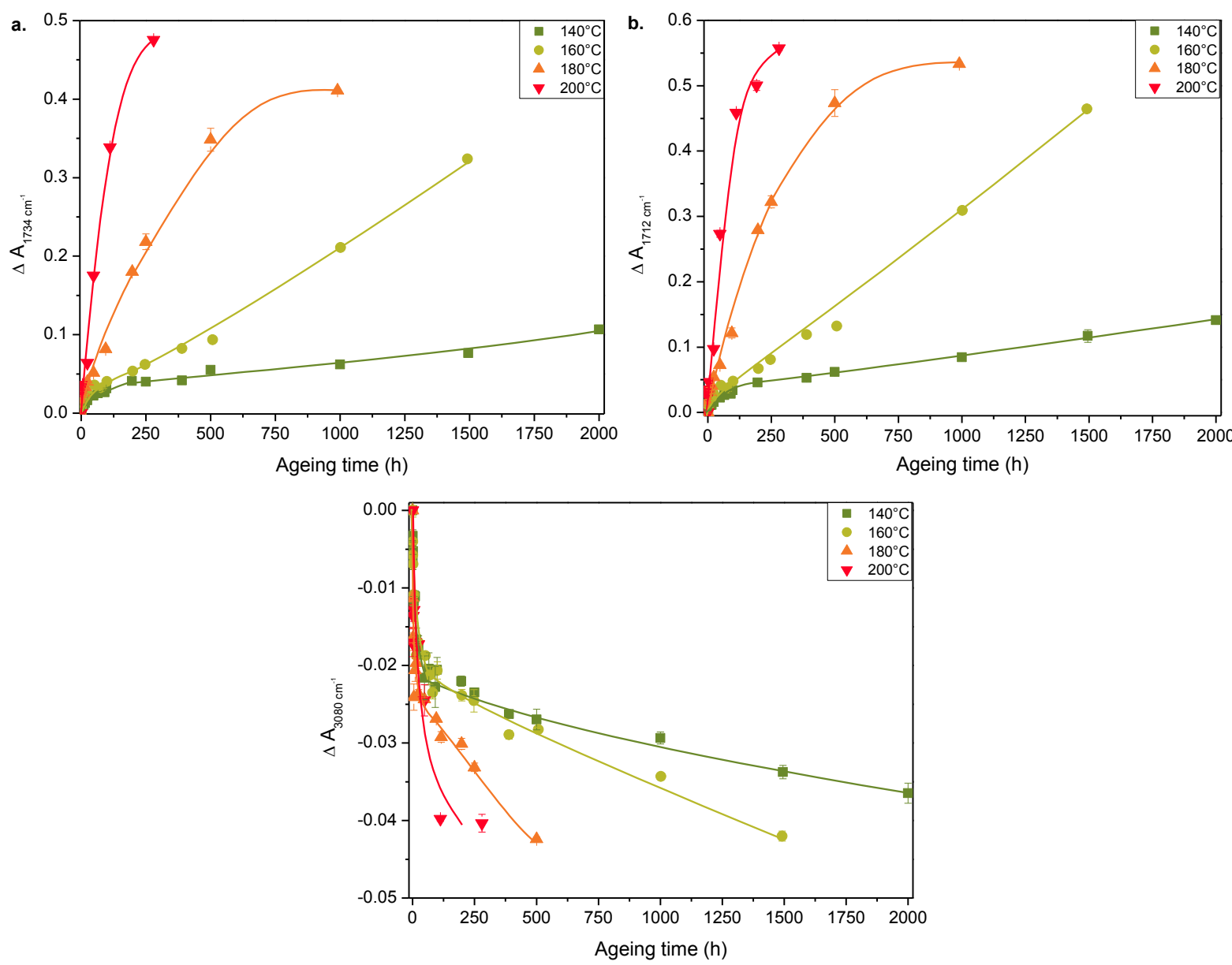

Fig.4 Absorbance variations at $1734 \mathrm{~cm}^{-1}\left(\right.$ a), $1712 \mathrm{~cm}^{-1}\left(\right.$ b) and $3080 \mathrm{~cm}^{-1}($ c) during thermal ageing of PA 6,6

In Figs. 4 a to c, no induction period was observed. This has already been observed with other polyamides and was attributed to the instability of hydroperoxides. [32,33]. Regarding Figs 4. $a$ and $b$, the results reported for the four temperatures indicate that the absorbances at 1734 $\mathrm{cm}^{-1}$ and $1712 \mathrm{~cm}^{-1}$ increased with increasing ageing time. As expected, for the same time of thermo-oxidation, the higher the ageing temperature was, the higher the oxidation product quantity. Fig 4.c indicated a marked decrease in the absorbance at $3080 \mathrm{~cm}^{-1}$ at an early stage after exposure (loss of more than $50 \%$ of the absorbance after only $125 \mathrm{~h}$ ). The rate at which the absorbance of amides decreases depends on the temperature. Since one expects a correlation between the disappearance of amides and the formation of oxidation products, the variations in $\mathrm{A}_{1734 \mathrm{~cm}^{-1}}$ vs $\mathrm{A}_{3080 \mathrm{~cm}^{-1}}$ and $\mathrm{A}_{1712 \mathrm{~cm}^{-1}}$ vs $\mathrm{A}_{3080 \mathrm{~cm}}^{-1}$ were plotted, as shown in Fig.5. 


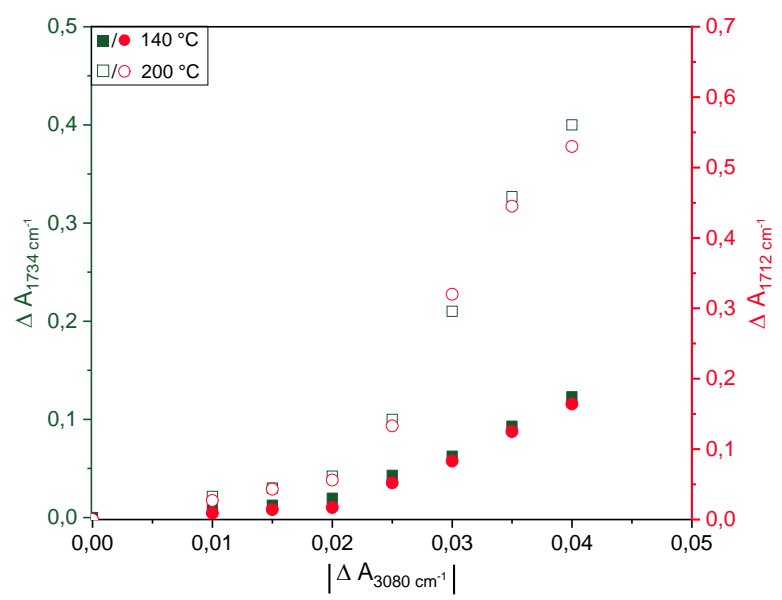
Fig. $5 \Delta A_{1734 \mathrm{~cm}^{-1}}$ vs $\Delta A_{3080 \mathrm{~cm}^{-1}}$ and $\Delta A_{1712 \mathrm{~cm}^{-1}}$ vs $\Delta A_{3080 \mathrm{~cm}}{ }^{-1}$ of the thermo-oxidized PA 6,6 sample between $1400^{\circ} \mathrm{C}$
and $200^{\circ} \mathrm{C}$

This graph indicates that the correlation between the oxidation bands and the amide band depended on the temperature.

At the same extent of amide band intensity decrease resulting from oxidation, the same quantity of imides/acids should be formed, independent of the temperature. Complementary results obtained by TGA and thickness measurements (see supplementary information) showed that the mass loss was approximately $4 \%$ at $140{ }^{\circ} \mathrm{C}$ and below $1 \%$ at $200{ }^{\circ} \mathrm{C}$ for the same decrease in the absorbance at $3080 \mathrm{~cm}^{-1}$. The cross-sectional microscopy images of samples oxidized at various temperatures (see supplementary information) clearly indicate that a non-negligible part of the sample has been lost in the case of the oxidation at $140{ }^{\circ} \mathrm{C}$ (500 hours at $140^{\circ} \mathrm{C}$ ) whereas no significant loss was observed in the case of oxidation at 200 ${ }^{\circ} \mathrm{C}\left(25\right.$ hours at $\left.200^{\circ} \mathrm{C}\right)$, for the same decrease in the absorbance at $3080 \mathrm{~cm}^{-1}$. As shown in Fig. 5, at the same extent of amide band intensity reduction $\left(3080 \mathrm{~cm}^{-1}\right)$, the amount of oxidation products formed was lower at the lowest temperature. On the basis of the results found in the literature, an explanation ean could be proposed, which involves the progressive loss of volatile products containing imide and acid functions, the loss being more important at $140^{\circ} \mathrm{C}$ since the oxidation time is much more important. The formation of volatile products has been reported by Gröning et al. [13].

\section{1.b) SEC measurements}

Molar mass variation is expected to result from thermal oxidation as degradation leads to crosslinking or chain scission. [31,34] It is then important to evaluate how the average 
molecular weight is impacted by the chemical changes of the matrix. The molecular weights were determined by performing SEC measurements after the ageing experiments at $140{ }^{\circ} \mathrm{C}$ and $180{ }^{\circ} \mathrm{C}$. This technique is certainly the most appropriate, as rheometry and viscosity measurements require the polymer to be in the molten state, which is thus further exposed to heat. [27,35] Thin films were analysed to avoid the effects of oxygen diffusion. The obtained $\mathrm{M}_{\mathrm{n}}$ values are presented in Table.2.

Table.2. Modification of the $M_{n}$ of the samples aged under air at $140{ }^{\circ} \mathrm{C}$

\begin{tabular}{|c|c|c|}
\hline Ageing time (h) & $\mathrm{M}_{\mathrm{n}, 14{ }^{\circ}{ }^{\circ} \mathrm{C}\left(\mathrm{kg} \cdot \mathrm{mol}^{-1}\right)}$ & $\mathrm{M}_{\mathrm{n}, 180{ }^{\circ} \mathrm{C}}\left(\mathrm{kg} \cdot \mathrm{mol}^{-1}\right)$ \\
\hline 0 & 30 & 30 \\
\hline 4 & & 21 \\
\hline 10 & 19 & 15 \\
\hline 25 & 12 & 14 \\
\hline 100 & 8 & \\
\hline 200 & & \\
\hline
\end{tabular}

A decrease in $M_{n}$ was observed with exposure time suggesting that a chain scission mechanism was predominant. As reported above in the case of the C-N-H bonds (Fig.4.c), the rate was maximum at the beginning of exposure and decreased gradually with ageing time. In fact, $37 \%$ of the total decrease in molar mass was reached at $25 \mathrm{~h}$ of exposure at $140{ }^{\circ} \mathrm{C}$, this decrease was more drastic with increasing temperature.

Furthermore, SEC measurements can provide access to the quantification of chain scission and crosslinking processes. The number of chain scission (s) and crosslinking (x) events per mass unit can be assessed according to the Saito relationship assuming random chain scission and crosslinking processes:[36]

$$
\frac{1}{M_{n}}-\frac{1}{M_{n, 0}}=s-x
$$




$$
\frac{1}{M_{w}}-\frac{1}{M_{w, 0}}=\frac{s}{2}-2 x
$$

Fig.6 displays the numbers of chain scissions (s) and crosslinking (x) events as a function of exposure time during oxidative ageing at $140{ }^{\circ} \mathrm{C}$. This figure compares thin films (300 microns) with thick plates (1500 microns). In the case of thick plates, oxidation is limited to the outer layers whereas in the case of the thin films, no oxidation profile is observed. One of the consequences is an under evaluation of the modifications of molecular mass in the case of thick plates, since SEC measurements take into account the whole thickness of the samples, which means a large part of unoxidized polymer.

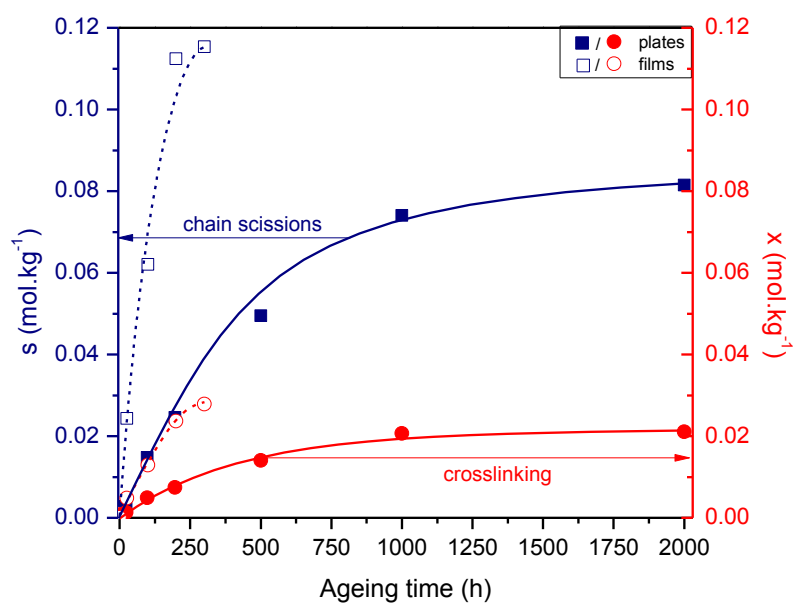

Fig.6 Chain scission ( $s)$ and crosslinking $(x)$ numbers as a function of ageing time under air exposure at $140{ }^{\circ} \mathrm{C}$ (thin films vs thick plates)

The number of chain scission events increased until $1000 \mathrm{~h}$ of ageing and then reached a plateau, while there was a slight increase in the number of crosslinking events, which also achieved a plateau at $1000 \mathrm{~h}$ of ageing. Saito's equations confirmed that chain scissions events dominated over crosslinking; however, crosslinking still occurred to some extent. For samples aged under a long period of time $(>500 \mathrm{~h})$, the oxidation process was heavily advanced and led to the presence of insoluble parts in the material. These insoluble parts suggest that crosslinking is occurring at a higher amount than calculated.

3.2) Modification of the macromolecular architecture

The morphological modifications, which occurred as a result of the thermo-oxidation process in the PA 6,6 samples, were analysed by differential scanning calorimetry (DSC). DSC 
measurements were performed with PA 6,6 plates. Fig.7 shows the DSC thermograms of the samples aged for $30 \mathrm{~min}$ at each temperature.

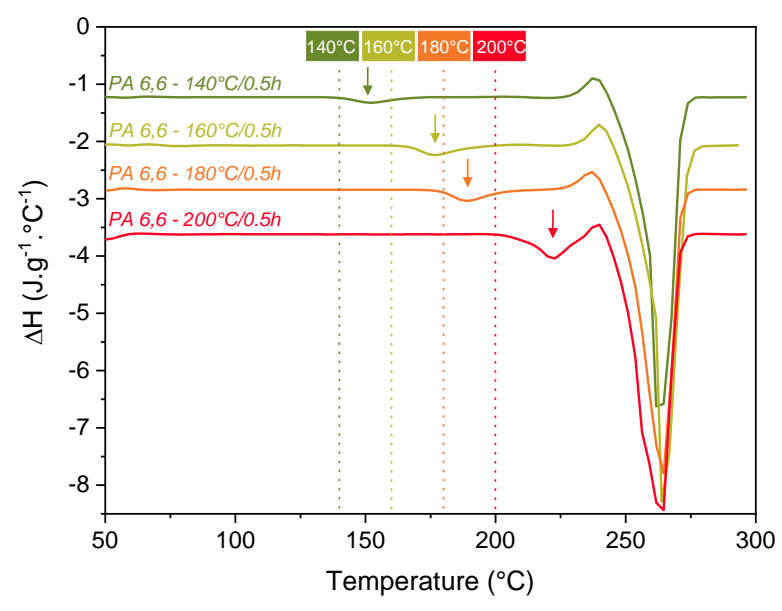

Fig.7 DSC thermograms of PA 6,6 aged for 30 min at each temperature (first heating step)

In each thermogram, one can observe an exothermic peak prior to the endothermic melting peak at $265^{\circ} \mathrm{C}$. This peak, previously observed by Khanna in PA 6, PA 6,6 and PA 12, was attributed to a new sub-melting temperature transition. [37] In the literature, the development of this exotherm is attributed to the rapid cooling of polymers. [37-39] During processing, polyamide melted at $320{ }^{\circ} \mathrm{C}$ and then moulded at $70{ }^{\circ} \mathrm{C}$, which caused quenching of the material. When the samples were aged at a temperature above the glass transition temperature $\left(\mathrm{T}_{\mathrm{g}}=65^{\circ} \mathrm{C}\right)$, there was a release of the internal stresses induced by quenching.

Moreover, a smaller endothermic peak was recorded approximately $10-30{ }^{\circ} \mathrm{C}$ above the ageing temperature (indicated by the arrows in Fig.7.). Some authors have attributed this peak to the melting of microcrystals formed in the amorphous region. [40,41] The formation of these microcrystallites can be attributed to a post-crystallisation effect, as the samples are aged at a temperature above $\mathrm{T}_{\mathrm{g}}$. Structural changes during post-crystallisation can occur as chain rearrangements caused by hydrogen bond breaking, relaxation of tie-molecules and increased chain motion. [42] According to Shu et al., mobile chains in the amorphous region can combine with the crystallites as the chain motion increases, causing an increase in the crystallinity. [43]

To discriminate between the post-crystallisation effect and thermo-oxidation, some samples were aged in the absence of oxygen (i.e. experimental part). The DSC first heating curves of 
the thermo-oxidized samples (straight lines) and the aged samples without oxygen (dotted lines) at different ageing times at $160{ }^{\circ} \mathrm{C}$ were then compared and are shown in Fig.8. The crystallinity evolution calculated from the thermograms is presented in Fig.9.

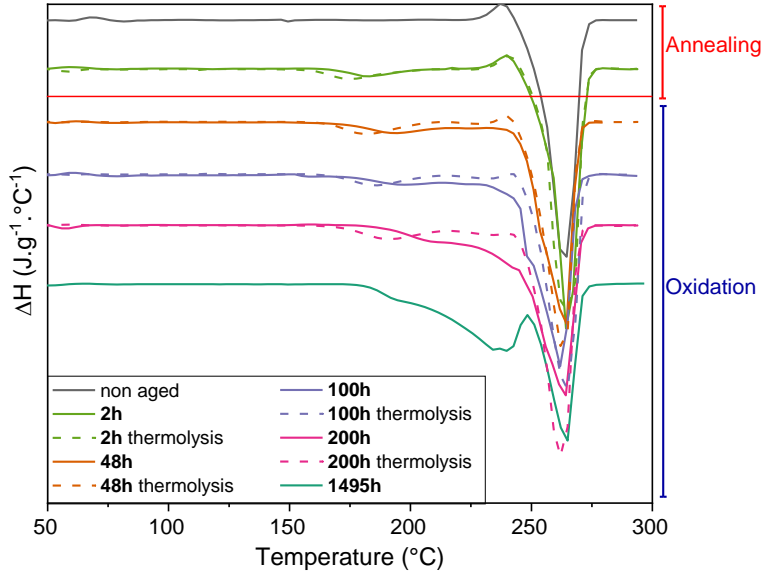

Fig. 8 DSC thermograms of PA 6,6 aged at $160^{\circ} \mathrm{C}$ in an oven with or without $\mathrm{O}_{2}$

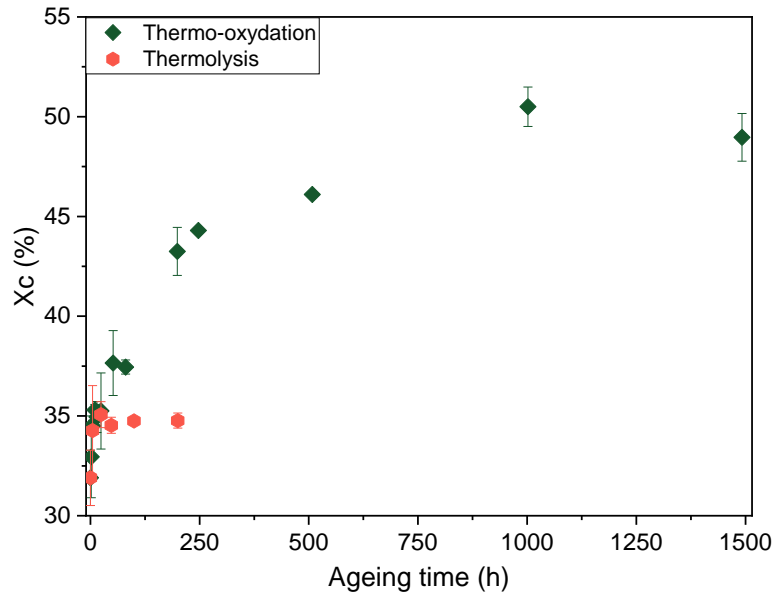

Fig.9 Crystallinity evolution during an oven ageing at $160{ }^{\circ} \mathrm{C}$ with or without $\mathrm{O}_{2}$

In the early stage of exposure, corresponding to the first $48 \mathrm{~h}$ at $160{ }^{\circ} \mathrm{C}$, the significant increase in the crystallinity can be attributed to the post-crystallisation process, as the DSC curves and the crystallinity values are similar between the samples aged in the presence or absence of oxygen. We can assume that until $48 \mathrm{~h}$ of exposure at $160{ }^{\circ} \mathrm{C}$, the postcrystallisation effect is predominant over oxidation (although the oxidation process cannot be excluded). Then, as shown in Fig.9, the crystallinity ratio of samples aged without oxygen reached a plateau at $35 \%$ while the crystallinity ratio of thermo-oxidized samples still increased. This finding led us to assume that the end of the post-crystallisation process was reached after $48 \mathrm{~h}$ of exposure at $160{ }^{\circ} \mathrm{C}$.

After $48 \mathrm{~h}$, the melting endotherms of the thermo-oxidized samples contained a large melting peak at the lower temperatures, indicating a broad distribution in the crystal thickness, while the sub-melting temperature peak disappeared. With increasing ageing time, one can observe a new peak at $170{ }^{\circ} \mathrm{C}$ close to the main melting peak at $265^{\circ} \mathrm{C}$, suggesting a modification of the crystalline morphology. During thermo-oxidative ageing, chain scissions occur exclusively in the amorphous phase since crystalline fractions remain impermeable to oxygen. $[43,44]$ The literature indicates that chain scission can result in an increase in crystallinity, as chain fragments released by chain scissions in the amorphous phase can integrate into the crystalline phase if their mobility is high enough, which is known as chemi-crystallization 
[34,45-47]. However, since DSC heating curves show a wide crystal distribution at lower temperatures, it is noteworthy to consider the formation of new crystals arising from the reorganization of chain fragments. These crystals are smaller than those formed by lamellar thickening, and thus melt at lower temperatures, as already demonstrated by Thanki et al. in their study of PA 6,6 photooxidation. [48]

3.3) Deterioration of the functional properties

\section{3.a) Yellowing}

The discolouration of the PA 6,6 plates of $1500 \mu \mathrm{m}$ thickness with ageing time was examined by UV-VIS spectroscopy. Spectra were recorded for samples aged at $140{ }^{\circ} \mathrm{C}$ at various times of exposure. A large shoulder between $280 \mathrm{~nm}$ and $480 \mathrm{~nm}$ appeared in conditions of thermaloxidation, which increased in intensity during exposure. The samples became progressively yellow. Monitoring the absorbance at $450 \mathrm{~nm}$ allowed for a good perception of the colorimetric evolution of the material. [49] The kinetic curve of the changes in the absorbance at $450 \mathrm{~nm}$ of oxidized PA 6,6 at $140{ }^{\circ} \mathrm{C}$ is shown in Fig. 10.

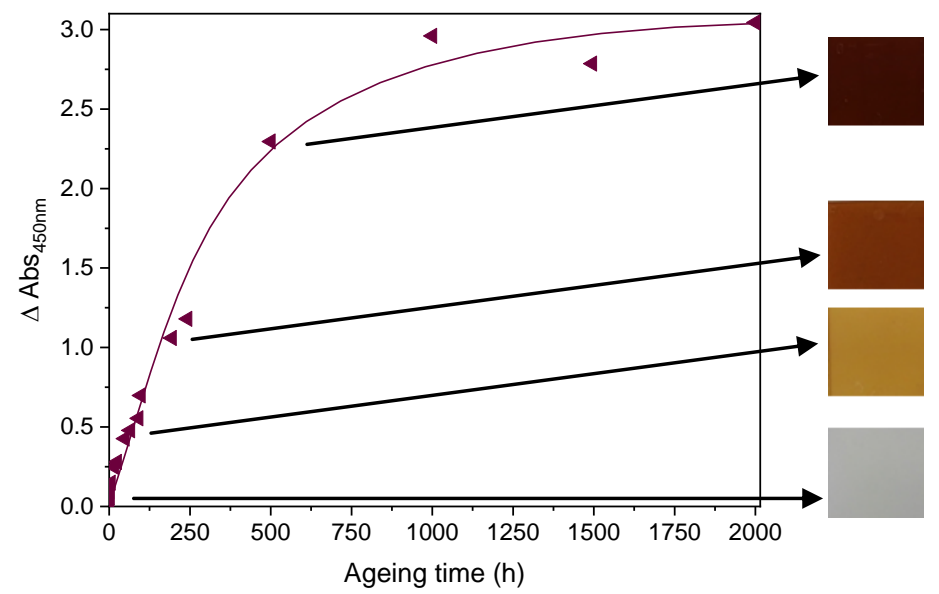

Fig.10 Changes in absorbance at $450 \mathrm{~nm}$ of the samples vs. oxidation time at $140{ }^{\circ} \mathrm{C}$

As shown in Fig.10, the absorbance at $450 \mathrm{~nm}$ showed the same trend as $\Delta \mathrm{A}_{3080 \mathrm{~cm}}{ }^{-1}$, crystallinity and chain scissions curves, namely a higher rate during the first stage of thermooxidation without an induction period. Photographs of the plates after $0,48 \mathrm{~h}, 98 \mathrm{~h}$ and $500 \mathrm{~h}$ of exposure are presented on the right-hand side of the figure. The modification of the colour was rapid, which gradually darkened until blackening for samples aged for more than $500 \mathrm{~h}$. 
According to the literature, the products responsible for yellowing of PA and their formation mechanisms are not fully understood and still subject of extensive researches. [50-53]

\section{3.b) Microhardness}

Microhardness is a convenient way to determine the mechanical properties on the surface of a polymer. The method consists of applying a sharp indenter with a given load onto a material surface and measuring the local deformation produced. Microhardness tests were performed on the surface of blank samples and samples aged at temperatures between $140{ }^{\circ} \mathrm{C}$ and 200 ${ }^{\circ} \mathrm{C}$. The shapes of the diamond marks left by the indenter on the PA 6,6 surfaces are shown in the supporting information. The modification of micro-hardness as a function of ageing time is shown in Fig.11.

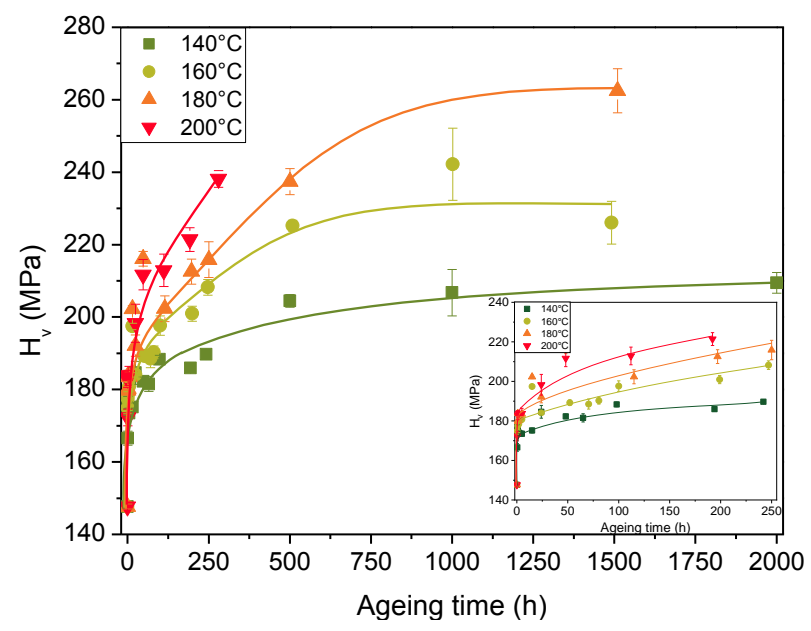

Fig. 11 Vickers $\mu$-hardness variations vs ageing time (from $140{ }^{\circ} \mathrm{C}$ to $200^{\circ} \mathrm{C}$ in the presence of oxygen)

Fig. 11 shows a marked increase in the sample hardness during the first $100 \mathrm{~h}$ of exposure (see insert). This large variation was observed for all ageing temperature. At temperature below $200{ }^{\circ} \mathrm{C}$, the Vickers microhardness seemed to reach a plateau for long-term exposure. In the case of thermo-oxidative ageing at $140{ }^{\circ} \mathrm{C}$, the hardness increase levelled off after $750 \mathrm{~h}$ of ageing.

These findings can be explained considering the increase in crystallinity resulting from oxidation. Lorenzo et al. previously found a linear relationship between micro-hardness and crystallinity for PP and PE [54]. The mechanical properties of semicrystalline polymers depend on the degree of crystallinity as crystals are stiffer and tougher than amorphous 
regions. It would therefore be expected that crystallinity and hardness evolve similarly under thermal ageing. [55]

In addition, PA 66 forms different crystal polymorphs whose development depends on the moulding conditions. The more stable $\alpha$-phase is developed upon slow cooling and the chains are organized in a triclinic unit cell. A pseudohexagonal $\gamma$-mesophase is formed upon quenching the melt and is only metastable at lower temperatures. [56] Upon heating, this $\gamma$ mesophase converts irreversibly into the $\alpha$-phase. [57] It has been previously shown that micro-indentation hardness values can be used to distinguish changes in the crystalline lattice of a polymer. $[58,59]$ The initial steep increase in the microhardness with ageing time can also be associated with the transformation of the $\gamma$-phase into the $\alpha$-phase, the latter having a larger hardness value. These variations in the hardness values between the two phases can be due to a difference in the densities of crystal nucleation. [60]

\section{4) Multiscale correlations}

The aim was to establish correlations between the chemistry of thermo-oxidation and the deterioration of the functional properties. It is particularly important to determine relevant probes to quantify the oxidation of PA 6,6 and reflect changes in the macromolecular properties. The carbonyl index is commonly used to monitor chemical changes induced by ageing and is often considered to be well-connected with the mechanical properties. [61] However, its reliability is questioned in certain cases, for instance, in the case of polypropylene photooxidation, where degradation induces the formation of volatile oxidation products, which are not detected by infrared analysis of the solid polymeric matrix. [62] In semicrystalline polymers, the complex morphology and chain scissions largely impact the mechanical properties such as elongation at break, affecting the correlations between both properties. [63] As discussed in the previous section, the degradation of PA 6,6 during thermo-oxidation arises from a chain radical mechanism, which leads to the disappearance of an amide function at $3080 \mathrm{~cm}^{-1}$ in addition to the following:

- Formation of oxidation products, mainly imides and carboxylic acids

- Chains scission responsible for the formation of carbonyl compounds

- Crystallinity and $\mu$-hardness increase 
On the basis of our experimental results, some comparisons can be made to gain a better understanding of the relationship between the modifications of various properties of polyamide 6,6 oxidized at a relatively high temperature $\left(140{ }^{\circ} \mathrm{C}-200{ }^{\circ} \mathrm{C}\right)$. The aim was to determine whether the loss of functional properties was correlated with the chemical changes, which were monitored by measuring the absorbance at $3080 \mathrm{~cm}^{-1}$ ("overtone" amide II band). In Fig.12, the absorbance of amides is plotted as a function of ageing time (left scale). Simultaneously, the changes in the molar mass are plotted (right scale) for the same conditions of ageing.

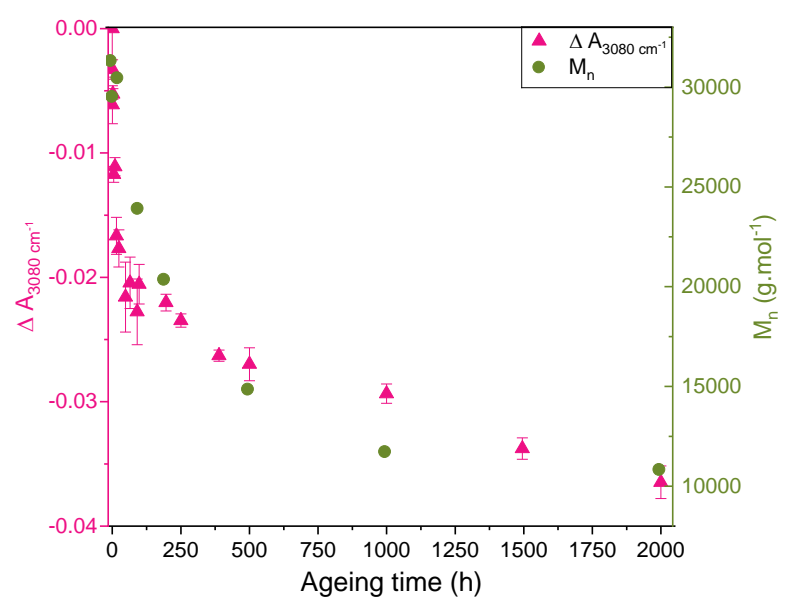

Fig.12 $\triangle A_{3080 \mathrm{~cm}-1}$ and molar mass as a function of thermal ageing time at $140{ }^{\circ} \mathrm{C}$

This figure indicated that the two curves followed the same trend implying a good correlation between the chemical changes and the molar mass modifications.

To evaluate the interconnection between macromolecular architecture and microstructure, we plotted the variations in the crystallinity (left scale) and molar mass (right scale) with ageing time in Fig.13-left. We also plotted the variation of crystallinity with molar mass (Fig. 13right). 

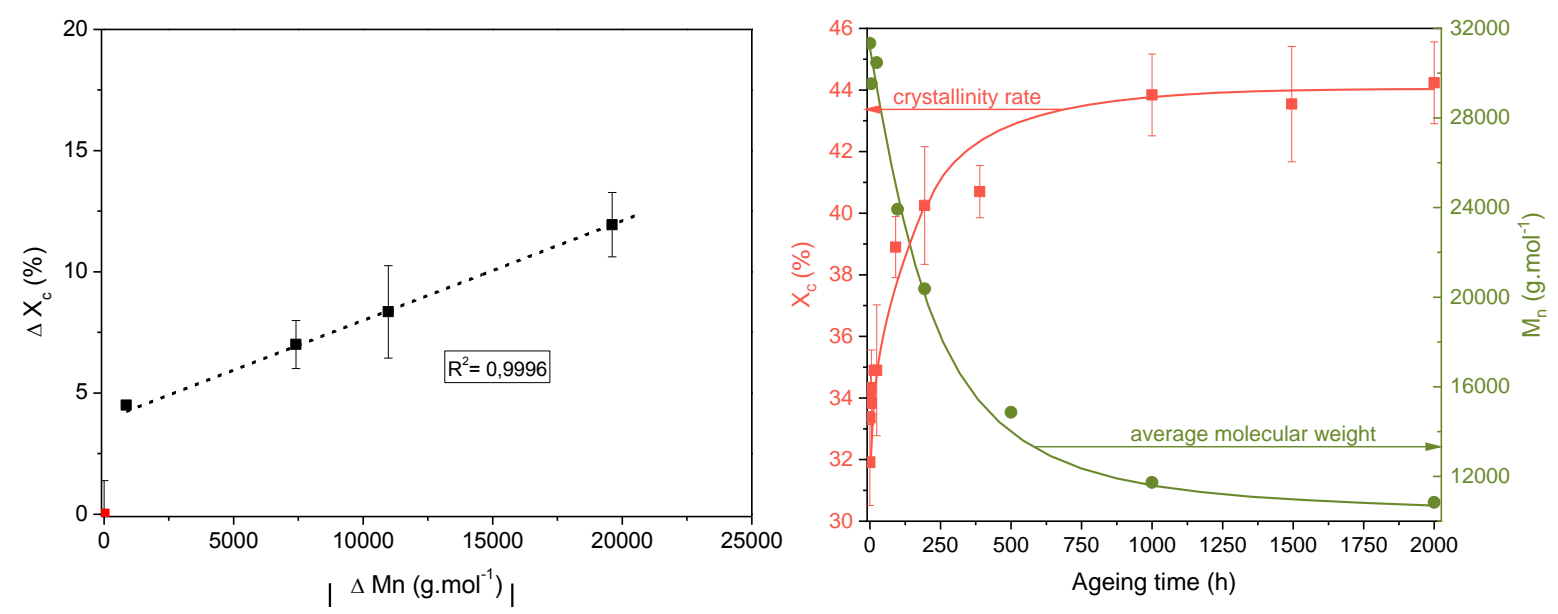

Fig.13 Variations in molar mass and crystallinity during oven ageing at $140{ }^{\circ} \mathrm{C}$ (left) and variation of crystallinity with molar mass (right)

Predictably, the crystallinity increased when the molecular weight decreased. In both curves, the changes in the kinetic rate took place simultaneously. The decrease in the molecular weight indicated that the predominance of the chain scission process was caused by the increase in the crystallinity. Fig 13- right also indicates that the crystallinity varies linearly with the molar mass.

To evaluate the modifications of the macromolecular architecture, the thermo-oxidative degradation was characterized by DSC and SEC, shown above, and by DMA analysis to determine $\tan \delta$. The complete results of the DMA analysis are presented in the supporting information. We observed a decrease in the $\tan \delta$ peak maximum, which indicated a loss in molecular mobility. [64] The variations in the crystallinity and maximum of $\tan \delta$ peak with thermal ageing at $140{ }^{\circ} \mathrm{C}$ are shown in Fig.14-left and the variation of crystallinity in function of maximum of $\tan \delta$ peak is shown in Fig 14-right.
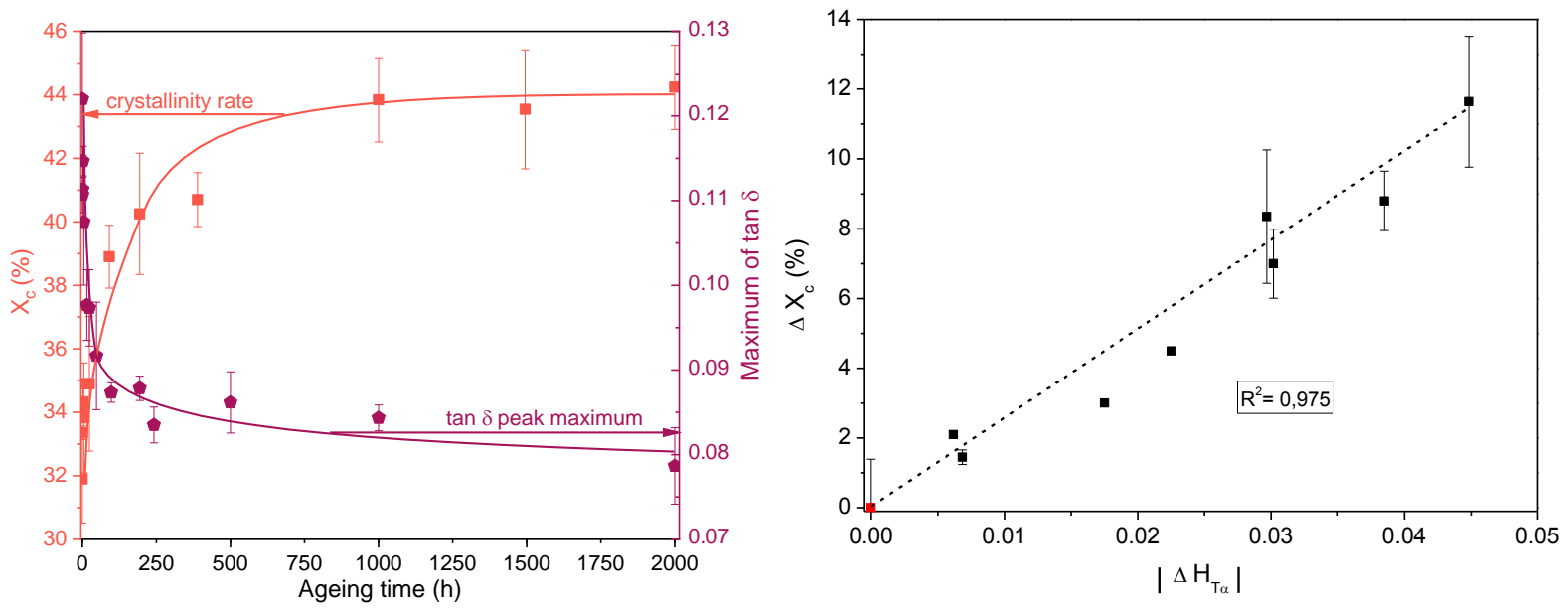
Fig. 14 Crystallinity and maximum of tan $\delta$ peak as a function of thermal ageing time at $140{ }^{\circ} \mathrm{C}$ (left) and variation of crystallinity in function of maximum of tan $\delta$ peak (right)

As expected, the decrease in the molecular mobility represented by the maximum of $\tan \delta$ was strongly related to the increase in crystallinity. As the crystallinity modification was strongly interconnected with both molar mass and molecular mobility, one can conclude that the microstructure and the macromolecular architecture of PA 6,6 were closely correlated and thus impacted in the same manner by thermal degradation. Fig 14- right indicates that the crystallinity varies linearly with the maximum of $\tan \delta$ peak.

The microhardness is directly related to the morphological and structural changes in a semicrystalline polymer. [65-68]

$$
H=\vartheta H_{c}+(1-\vartheta) H_{a}
$$

where $\mathrm{H}$ is the theoretical hardness, $v$ is the volume fraction of crystallized spherulites and $\mathrm{H}_{\mathrm{c}}$ and $\mathrm{H}_{\mathrm{a}}$ are the hardness of the crystalline and amorphous phases. The hardness of the crystalline and amorphous phases of PA 6,6 are equal to $463 \mathrm{MPa}$ and $65 \mathrm{MPa}$ respectively. [69]

In Fig.15, the crystallinity $\left(\mathrm{X}_{\mathrm{c}}\right)$ and Vickers micro-hardness $\left(\mathrm{H}_{\mathrm{v}}\right)$ are plotted as a function of ageing time at $200{ }^{\circ} \mathrm{C}$ and compared to the theoretical hardness $\mathrm{H}$ calculated from Eq.6. The inset shows the linear increase in the crystallinity with Vickers $\mu$-hardness.

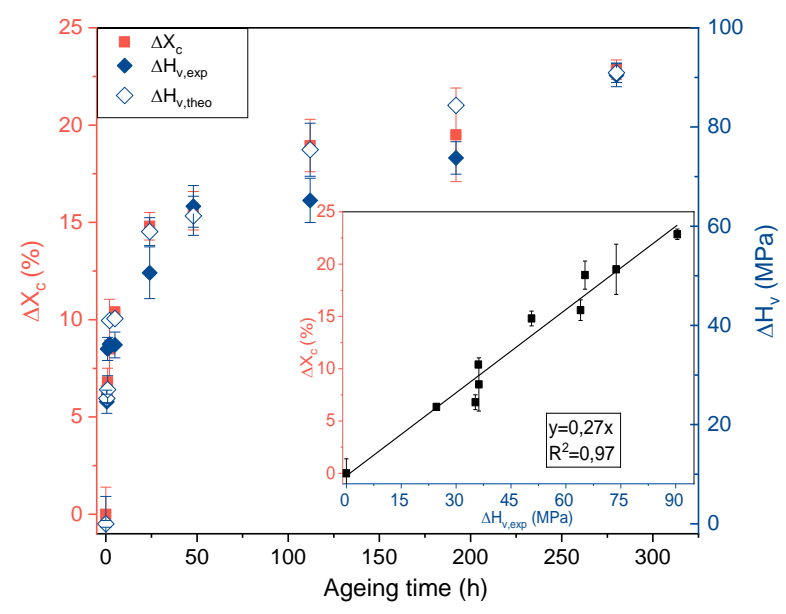

Fig.15 Kinetics of crystallinity and $\mu$-hardness Vickers under thermal ageing at $200{ }^{\circ} \mathrm{C}$ 
The data in Fig.15 indicate that the crystallinity increase was closely correlated to that of the microhardness. It is also important to note that the calculated hardness values are in complete agreement with the experimental hardness data. This result shows a pseudo-quantitative correlation between these two measurement scales and between the physical properties and the macromolecular architecture. On this basis, we can establish a relationship between the crystallinity and the corresponding local mechanical properties measured through the microhardness. The relation was determined after exposure of the PA 6,6 samples at $200{ }^{\circ} \mathrm{C}$ and can be written as follows:

$$
\Delta X_{c}=0,27 \times \Delta H_{v} \quad \text { Eq.6 }
$$

Direct correlations were drawn between changes in the chemical structure, modification of the microstructure and thermal/mechanical properties and this whatever the measurement scales, ranged from the molecular to the macroscopic scale. The same correlations (chemical structure- macromolecular properties) were found for all the studied temperatures and the results are presented in the supporting information.

\section{5) Conclusion}

The decrease in absorbance of the overtone of the amide II band at $3080 \mathrm{~cm}^{-1}$ was shown to be the best probe for oxidative degradation. At the molecular level, chain scissions predominated largely over crosslinking, regardless of the exposure conditions. At the macromolecular scale, the post-crystallisation process predominated at first, and then oxidation dominated. Both processes led to an increase in crystallinity. At scales corresponding to the functional properties, the oxidation caused yellowing, as shown by the increase in the absorbance at 450nm, and an increase in the Vickers microhardness. The modification of the overtone of the amide II band was correlated with the change in the molecular weight, which was directly connected to the increase in the crystallinity. This last parameter was also reflected by the microhardness. All of these PA 6,6 properties were proven to be reliable criteria for the multiscale characterization of the thermo-oxidative degradation of polyamides. The multiscale approach shows good correlations between the various scales under study and the exposure conditions (see supporting information). 
In a next communication, the influence of oxygen diffusion on the thermo-oxidation of polyamides will be investigated in a multiscale approach.

\section{Acknowledgments}

The authors wish to thank Schneider Electric and ANRT for financial support, and Dupont TM and Philippe Miniou for the sample preparation. 


\section{References}

[1] Mark HF. Encyclopedia of polymer science and technology. 3rd Edition. New-York: Wiley; 2007.

[2] Chailan JF, Boiteux G, Chauchard J, Pinel B, Seytre G. Effects of thermal degradation on the viscoelastic and dielectric properties of chlorosulfonated polyethylene (CSPE) compounds. Polym Degrad Stab 1995;48:61-65.

[3] Van Krevelen DW, Nijenhuis KT. Properties of polymers: their correlation with chemical structure; their numerical estimation and prediction from additive group contributions 2009(4)

[4] Chisca S, Musteata VE, Sava I, Bruma M. DIelectric behavior of some aromatic polyimide films. Eur Polym J 2011;47:1186-1197.

[5] Dong W, Gijsman P. Influence of temperature on the thermo-oxidative degradation of polyamide 6 films. Polym Degrad Stab 2010;95:1054-1062.

[6] Charles J, Ramkumaar GR, Azhagiri S, Gunasekaran S. FTIR and thermal studies on nylon-66 and 30\% glass fibre reinforced nylon-66. E-J Chem 2009;6(1):23-33.

[7] Karstens T, Rossbach V. Thermo-oxidative degradation of polyamide 6 and 6,6 Structure of UV/VIS-active chromophores. Makromol Chem 1990;191;757-771.

[8] Murty EM, Yehl TW. Adaptation of photoacoustic Fourier transform infrared spectroscopy for studying the thermal oxidation of nylon 66 at $15 \mathrm{O}^{\circ} \mathrm{C}$ correlated to mechanical properties.Polym Eng Sci 1990;30(24):1595-1598.

[9] George GA. An oxyluminescence investigation of the auto-oxidation of nylon 66. Polym Degrad Stab 1979;1(3):217-236.

[10] Grigg M.N. Thermo-oxidative degradation of polyamide 6, PhD Thesis, Queensland University of Technology, Australia; 2006. 
[11] Cerruti P, Carfagna C, Rychly J, Matisova-Rychla L. Chemiluminescence from oxidation of polyamide 6-6. I. The oxidation of pure polyamide. Polym Degrad Stab 2003;82:477-485.

[12] Frosstrom D, Reitberger T, Terselius B. Thermo-oxidative stability of polyamide 6 films. II. Chemiluminescence techniques. Polym Degrad Stab 2000;67:255-261.

[13] Gröning M, Hakkarainen M. Headspace solid-phase microextraction - a tool for new insights into the long-term thermo-oxidation mechanism of polyamide 6.6. J Chromatogr A 2001;932:1-11.

[14] Ania F, Martinez-Salazar J, Balta-Calleja F. Physical ageing and glass transition in amorphous polymers as revealed by microhardness. J Mat Sci 1989;24:2934-2938.

[15] Rivaton A, Gardette JL, Mailhot B, Morlat-Therias S. Basic aspects of polymer degradation. Macromol Symp 2005;225:129-146.

[16] Gardette JL. Infrared spectroscopy in the study of the weathering and degradation of polymers. Handbook of Vibrational Spectroscopy 2006

[17] Pearce EM, Bulkin BJ, Ng MY. Fourier transform IR spectroscopy for the study of polymer degradation. Thermal and thermooxidative degradation of polyethylene terephthalate. Adv Chem 1983;203(33):571-593.

[18] Do CH, Pearce EM, Bulkin BJ, Reimschuessel HK. FT-IR spectroscopic study on the thermal and thermal oxidative degradation of nylons. J Polym Sci Polym Chem 1987;25:2409-2424.

[19] Cannon CG. The infra-red spectra and molecular configuration of polyamides. Spectrochim Acta 1960;16:302-319.

[20] Lim LT, Britt IJ, Tung MA. Sorption and transport of water vapour in nylon 66 film. J Appl Poly Sci 1999;71:197-206.

[21] Roberts MF, Jenekhe SA. Site-specific reversible scission of hydrogen bonds in polymers. An investigation of polyamides and their Lewis acid-base complexes by infrared spectroscopy. Macromol 1991;24:3142-3146. 
[22] Tang L, Sallet D, Lemaire J. Photochemistry of polyundecanamides 1. Mechanisms of photooxidation at short and long wavelengths. Am Chem Soc 1982;15(5):1432-1437.

[23] Roger A, Sallet D, Lemaire J. Photochemistry of aliphatic polyamides 4. Mechanisms of photooxidation of polyamide 6,11 and 12 at long wavelengths. Macromol 1986;19:579-584.

[24] Socrates G. Infrared and Raman characteristic group frequencies. 3rd ed. Chichester: Wiley \& Sons Ltd; 2001.

[25] Arnaud R, Fanton E, Gardette JL. Photochemical behaviour of semi-aromatic polyamides. Polym Degrad Stab 1994;45(3):361-369.

[26] Lemaire J, Gardette JL, Rivaton A, Roger A. Dual photo-chemistries in aliphatic polyamides, Bisphenol A polycarbonate and aromatic polyurethanes - A short review. Polym Degrad Stab 1986;15:1-13.

[27] Sagar BF. Autoxidation of n-alkyl amides. Part III. Mechanism of thermal oxidation. J Chem Soc Phys Org 1967; 1047-1061.

[28] Okamba-Diogo O, Richaud E, Verdu J, Fernagut F, Guilment J, Fayolle B. Molecular and macromolecular structure changes in polyamide 11 during thermal-oxidation. Polym Degrad Stab 2014;108:123-132.

[29] El-Mazry C, Ben Hassine M, Correc O, Colin X. Thermal oxidation kinetics of additive free polyamide 6-6. Polym Degrad Stab 2013;98:22-36.

[30] Richaud E, Okamba Diogo O, Fayolle B, Verdu J, Guilment J, Fernagut F. Review: Auto-oxidation of aliphatic polyamides. Polym Degrad Stab 2013;98:1929-1939.

[31] Chionna D, Puglisi D, Samperi F, Montaudo G, Turturro A. Thermal oxidation products of nylon 6 determined by MALDI-TOF mass spectrometry. Macromol Rapid Commun 2001;22:524-529.

[32] Lánská B, Matisová-Rychlá L, Rychlý J. Chemiluminescence of polyamides: I. Luminescence accompanying autoxidation of lactams and thermolysis of lactam hydroperoxides. Polym Degrad Stab 1998;61:119-127. 
[33] Lánská B, Matisová-Rychlá L, Brožek, Rychlý J. Chemiluminescence of polyamides II. Luminescence accompanying thermooxidation of lactam-based polyamides related to the content of end-groups of molecules. Polym Degrad Stab 1999;66:433-444.

[34] Okamba-Diogo, Richaud E, Verdu J, Fernagut F, Guilment J, Fayolle B. Investigation of polyamide 11 embrittlement during oxidative degradation. Polymer 2016;82:49-56.

[35] Chen J, Radke W, Pasch H. Analysis of polyamides by size exclusion chromatography and laser light scattering. Macromol Symp 2003;193(1):107-118.

[36] Saito O. On the effect of high energy radiation to polymers I. Cross-linking and degradation. J Phys Soc Japan 1958;13(2):198-206.

[37] Khanna YP. Overview of transition phenomenon in nylon 6. Macromolecules 1992;25:3298-3300.

[38] Khanna YP, Kuhn WP. Measurement of crystalline index in nylons by DSC: complexities and recommendations. J Polym Sci Polym Phys 1997;35:2219-2231.

[39] Li B, Li C, Zhao D, Xu J, Fan Q. Investigation of the sub-melting-temperature exotherm in melt-quenched polyamide-6/clay nanocomposites. J Polym Sci Polym Phys 2005;43(4):378-382.

[40] Khanna YP. Evaluation of thermal history of polymeric films and fibers using DSC/TMA/DMA techniques. J Appl Polym Sci 1990;40:569-579.

[41] Oswald HJ, Turi EA, Harget PJ, Khanna YP. Development of a middle endotherm in DSC thermograms of thermally trated drawn PET yarnd and its structural and mechanistic interpretation. J Macromol Sci Phys 1977;13(2):231-254.

[42] Eriksson PA, Boydell P, Eriksson K, Manson JAE, Albertsson AC. Effect of thermaloxidative aging on mechanical, chemical and thermal properties of recycled polyamide 66. J Appl Polym Sci 1997;65(8):1619-1630.

[43] Shu Y, Ye L, Yang T. Study on the long-term thermal-oxidative aging behaviour of polyamide 6. J Appl Polym Sci 2008;110:945-957. 
[44] Hawkins WL, Matreyek W, Winlows FH. The morphology of semi-crystalline polymers. Part I. The effect of temperature on the oxidation of polyolefins. J Polym Sci 1959;41(138):1-11.

[45] Craig IH, White JR. Crystallization and chemi-crystallization of recycled photodegraded polypropylene. Polymer 2005;46(2):505-512.

[46] Rabello MS, White JR. Crystallization and melting behaviour of photodegraded polypropylene - I. Chemi-crystallisation

[47] Zhao Y, Luo Y, Jiang B. Effect of irradiation on crystallinity and mechanical properties of ultrahigh molecular weight polyethylene. J Appl Polym Sci 1993;50(10):1797-1801.

[48] Thanki PN, Ramesh C, Singh RP. Photo-irradiation induced morphological changes in nylon 66. Polymer 2001;42:535-538.

[49] Real LP, Gardette JL. Ageing and characterisation of PVC-based compounds utilised for exterior applications in the building construction field: 1: Thermal ageing. Polym Test 2001;20(7):779-787.

[50] Li R, Hu X. Study on discoloration mechanism of polyamide 6 during thermooxidative degradation. Polym Degrad Stab 1998;62:523-528.

[51] Karstens T, Rossbach V. Thermo-oxidative degradation of polyamide 6 and 6,6. Makromol Chem 1989;190:3033-3053.

[52] Marek B, Lerch E. Photodegradation and yellowing of polyamides. J Soc Dyers Colour 1965;81(11):481-487.

[53] Fromageot D, Roger A, Lemaire J. Thermooxidation yellowing of aliphatic polyamides. Angew Makromol Chem 1989;170:71-85.

[54] Lorenzo V, Perena JM, Fatou JG. Vickers microhardness related to mechanical properties of polypropylene. J Mater Sci Lett 1989;8:1455-1457. 
[55] Bayer RK, Balta Calleja FJ, Kilian HG. Crystal hardness and average distance between stable entanglements in melt crystallized polyethylene. Colloid Polym Sci $1997 ; 275: 432-439$.

[56] Russel DP, Beaumont PWR. Structure and properties of injection-moulded nylon-6: Part 1 Structure and morphology of nylon-6. J Mater Sci 1980;15:197-207.

[57] Androsch R, Stolp M, Radusch HJ. Crystallization of amorphous polyamides from the glassy state. Acta Polym 1996;47:99-104.

[58] Balta Calleja FJ, Martinez Salazar J, Asano T. Phase changes in isotactic polypropylene measured by microhardness. J Mater Sci 1988;7:165-166

[59] Azzurri F, Flores A, Alfonso GC, Sics I, Hsiao BS, Balta Calleja FJ. Polymorphism of isotactic polybutene-1 as revealed by microindentation hardness. Part II: correlations to microstructure. Polymer 2003;44(5):1641-1645.

[60] Azzurri F, Flores A, Alfonso GC, Balta Calleja FJ. Polymorphism of isotactic poly(1butene) as revealed by microindentation hardness. 1. Kinetics of the transformation. Macromolecules 2002;35:9069-9073.

[61] Forsstrom D, Terselius B.Thermo oxidative stability of polyamide 6 films. I. Mechanical and chemical characterization. Polym Degrad Stab 2000;67:69-78.

[62] Rouillon C, Bussiere PO, Desnoux E, Collin S, Vial C, Therias S, Gardette JL. Is carbonyl index a good probe to monitor polypropylene degradation ? Polym Degrad Stab 2016;128:200-208.

[63] Celina M. Review of polymer oxidation and its relationship with materials performance and lifetime prediction. Polym Degrad Stab 2013;98:2419-2429.

[64] Menczel JD, Prime RB. Thermal Analysis of Polymers: Fundamentals and Applications. 1st ed. New-York: John Wiley \& Sons; 2009.

[65] Bartolomeo P, Irigoyen M, Aragon E, Frizzi MA, Perrin FX. Dynamic mechanical analysis and Vickers micro hardness correlation for polymer coating UV ageing characterization. Polym Degrad Stab 2001;72:63-68. 
[66] Katare R, Bajpai R, Datt SC. Microhardness testing to detect radiation-induced crosslinking in polystyrene: poly(methylmethacrylate) polyblends. Polym Test 1994;13(2):107-112.

[67] Ania F, Martinez-Salazar J, Balta-Calleja FJ. Physical ageing and glass transition in amorphous polymers as revealed by microhardness. J Mater Sci 1989;24:2934-2938.

[68] Santa-Cruz C, Balta-Calleja FJ, Zachmann HG, Stribeck N, Asano T. Relating microhardness of poly(ethylene terephthalate) to microstructure. J Polym Sci B Polym Phys 1991;29:819-824.

[69] Krache R, Benachour D, Cagiao ME, Balta-Calleja FJ, Bayer RK, Tschöpe F. Micromechanical studies on binary and ternary blends of polyethylene, polypropylene and polyamide 66: Influence of the compatibilizer. Intern J Polym Mater Polym Biomater 2003;52(10):939-956.

[70] Chandler H, editor. Hardness testing. 2nd ed. ASM International, ISBN 0-87170-640$7 ; 1999$.

[71] Birkinshaw C, Buggy M, Daly S. Mechanism of ageing in irradiated polymers. Polym Degrad Stab 1988;22:285-294. 